\title{
Detection and identification of human papillomavirus using a PCR-restriction fragment mass polymorphism assay
}

\author{
JIN KYUNG LEE ${ }^{1}$, YOUNG JUN HONG ${ }^{1}$, TAE HYUN UM ${ }^{6}$, EUN HEE LEE ${ }^{7}$, \\ HYUN-SOOK $\mathrm{CHI}^{3}$, JAE SOO $\mathrm{KOH}^{2}$, HYEON WOO YIM ${ }^{4}$ and YOUNG JOO CHA ${ }^{5}$
}

\begin{abstract}
Departments of ${ }^{1}$ Laboratory Medicine, and ${ }^{2}$ Pathology, Korea Cancer Center Hospital, Seoul 139-706; ${ }^{3}$ Department of Laboratory Medicine, University of Ulsan College of Medicine and Asan Medical Center, Seoul 138-736; ${ }^{4}$ Department of Preventive Medicine, Catholic University of Korea College of Medicine, Seoul 137-701; ${ }^{5}$ Department of Laboratory Medicine, Chung-Ang University College of Medicine and Medical Center, Seoul 156-755; ${ }^{6}$ Department of Laboratory Medicine, Inje University College of Medicine and Ilsan-Paik Hospital, Goyang 411-706; ${ }^{7}$ Department of Laboratory Medicine, Green Cross Reference Laboratory, Kyunggi-do 446-770, Republic of Korea
\end{abstract}

Received January 18, 2011; Accepted April 12, 2011

DOI: $10.3892 / \mathrm{mmr} .2011 .475$

\begin{abstract}
A polymerase chain reaction-restriction fragment mass polymorphism (PCR-RFMP) assay protocol using PGMY09/11 primers for the detection and identification of human papillomavirus (HPV) has recently been developed. The present study evaluated the analytical sensitivity and clinical utility of HPV genotyping employing PCR-RFMP as compared to direct sequencing. Serial dilutions of cloned HPV DNA were analyzed in order to assess the limit of detection (LOD) and three sets of HPV clone mixtures (types 16+18, 16+11 and $18+11$ ) were used to assess the accuracy of the genotyping assays. For 423 cervical specimens that were cytologically categorized as normal or cancer, the concordance between the two assays was evaluated. Clinical sensitivity was calculated by evaluating 101 histologically confirmed cases. The PCR-RFMP HPV assay had a lower LOD and 100\% accuracy when detecting double HPV infection. Agreement between the two assays upon 423 clinical specimens was $91.0 \%$ with a $\kappa$-value of 0.86 . The incidence of multiple HPV infections among HPV-positive patients was $19.0 \%$ by PCR-RFMP and $5.4 \%$ by sequencing. The clinical sensitivity of PCR-RFMP and sequencing was $92 \%$ and $84 \%$, respectively. In conclusion, the PCR-RFMP assay for HPV genotyping correlated well with direct sequencing, provides high analytical and clinical sensitivity, and is advantageous in the detection of multiple HPV infections.
\end{abstract}

Correspondence to: Dr Young Joo Cha, Department of Laboratory Medicine, Chung-Ang University College of Medicine and Medical Center, 224-1 Heukseok-dong, Dongjak-gu, Seoul 156-755, Republic of Korea

E-mail: chayoung@cau.ac.kr

Key words: human papillomavirus, polymerase chain reactionrestriction fragment mass polymorphism, analytical sensitivity, clinical sensitivity, multiple infection

\section{Introduction}

Infection with human papillomavirus (HPV) is the cause of virtually all instances of invasive cervical cancer, which results in 275,000 deaths annually worldwide (1). More than 100 forms of HPV have been described and are classified as high- or low-risk types depending on oncogenicity (2). HPV types 16 and 18 cause $70 \%$ of all cervical cancers (3), whereas HPV types 6 and 11 give rise to $90 \%$ of cases of genital warts and laryngeal papillomas $(4,5)$. To study the natural history of $\mathrm{HPV}$, and to aid in vaccine development and the management of infected patients, the detection and genotyping of HPV DNA are crucial (6). Several molecular diagnostic tests for HPV genotyping have been developed, but to date no gold standard has been developed.

A polymerase chain reaction-restriction fragment mass polymorphism (PCR-RFMP) assay is based on PCR amplification and the precise sizing of oligonucleotides after genotype-specific base variation is detected by fragment scission using Type IIS restriction enzymes (7). Since the size of a PCR product is directly determined without the use of any fluorescent or radioactive tag, a PCR-RFMP assay can afford good analytical sensitivity and accuracy. PCR-RFMP has been useful when employed to genotype hepatitis $\mathrm{B}$ and $\mathrm{C}$ viruses (8-10), and a PCR-RFMP protocol for HPV genotyping using PGMY09/11 primers has recently been developed (11).

The aim of the present study was to evaluate the analytical sensitivity and clinical utility of HPV genotyping using the PCR-RFMP assay.

\section{Materials and methods}

Construction of DNA templates for HPV types 18, 16 and 11 . To evaluate the sensitivity of HPV detection using the PCR-RFMP assay, serially diluted HPV DNA clones were employed. Plasmid DNA containing the entire genomes of HPV types 18 (45152D), 16 (45113D) and 11 (45151D) were purchased from ATCC. Plasmid DNA $(20 \mathrm{~nm})$ were trans- 
formed into Escherichia coli HB101 competent cells (Takara, Otsu, Japan), which were then cultured on Luria-Bertani agar plates (USB, Cleveland, OH, USA) with ampicillin (Sigma, St. Louis, MO, USA) for $16 \mathrm{~h}$. Selected colonies were incubated in Luria-Bertani broth (USB) with ampicillin for $18 \mathrm{~h}$. The DNA of each HPV type was extracted using the Exprep GeneAll plasmid SV mini kit (GeneAll, Seoul, Korea).

Determination of limit of detection. Template DNA of plasmids carrying HPV types 16,18 and 11 were set into $2.5 \times 10^{5}$ copies/ $\mu 1$, from which they were serially diluted 10 -fold into $2.5 \times 10^{-1}$ copies/ $\mu 1$ with HPV-negative DNA prepared from cytologically normal cervical cells. HPV-negative DNA was prepared from pooled cervical cells collected from cytologically normal and HPV-negative women by Hybrid Capture II assay (Qiagen Inc., Valencia, CA, USA). Seven concentrations were tested in batches of 5 replicates on 5 separate days, giving a total of 25 replicates at each concentration. The limits of detection (LODs) of the PCR-RFMP assay and direct sequencing were calculated by probit analysis at $95 \%$ of detection using SPSS 13.0 (SPSS GmbH Software, Munich, Germany) and compared.

Identification of double infection of HPV genotypes. For HPV genotyping and detection of double genotype infections, three sets of HPV clonal mixtures (HPV types 16+18, 16+11 and $18+11)$ in various mass ratios $(9: 1,8: 2,5: 5,2: 8$ and 1:9) were tested by PCR-RFMP assay and by direct sequencing. Any mixture that was not correctly typed by either method was confirmed using type-specific PCR tests for HPV.

Concordance between PCR-RFMP and direct sequencing. A total of 423 thin-prep cervical specimens cytologically categorized into 5 classes were evaluated: normal, atypical squamous cells of undetermined significance (ASCUS), low-grade squamous intraepithelial lesion (LSIL), high-grade squamous intraepithelial lesion (HSIL) and squamous cell carcinoma (SCC). The Institutional Review Board for Research on Human Subjects of Chung-Ang University College of Medicine approved the protocol for the use of clinical specimens. DNA was extracted from thin-prep supernates using the QIAamp DNA Blood Mini kit (Qiagen, Chatworth, CA, USA) after cytological examination requested by clinicians, and sent to the HPV laboratories. PCR-RFMP and direct sequencing were separately performed in different laboratories. Concordance between PCR-RFMP and direct sequencing data were calculated using $\kappa$ statistics (SPSS GmbH Software). The incidence of multiple HPV infections among HPV-positive patients was also analyzed.

HPV PCR-RFMP. PGMY09/11 primers were used for firstround amplification in both the PCR-RFMP assay and direct sequencing (12). The general protocol of the PCR-RFMP test has been previously described (11). Briefly, $4 \mu 1$ of DNA were amplified with PGMY09/11 primers, comprising two non-degenerate pools of L1 consensus primers. Second round primer pairs comprised a sense primer RFMPF specific to bases 6584 to 6603 (5'-GCMCAGGGHCAYAAGGATGAA TGG-3') and an antisense primer RFMPR specific to bases 6657 to 6626 (5'-GTACTDCKDGTRGTATCHACMACG GATGTAACAAA-3'). The underlined 5-nucleotide sequence
(GGATG) embedded in the primers introduced a FokI site (a neoschizomer of $\mathrm{Bts} \mathrm{CI}$ ) in the amplicon. Restriction enzyme digestion of PCR products was performed by mixing the PCR reaction mixtures with $10 \mu \mathrm{l}$ of buffer containing $50 \mathrm{mM}$ potassium acetate, $20 \mathrm{mM}$ Tris-acetate, $10 \mathrm{mM}$ magnesium acetate, $1 \mathrm{mM}$ dithiothreitol and 1 unit of FokI and BtsCI. The reaction mixtures were incubated at $37^{\circ} \mathrm{C}$ for $1 \mathrm{~h}$. The resulting digest was purified by vacuum filtration through 96-well Oasis ${ }^{\circledR} \mu$ Elution Plates (Waters, Tokyo, Japan). The desalted reaction mixtures were resuspended with matrix solution containing $15 \mathrm{mg} / \mathrm{ml}$ 3-hydroxypicolinic acid, $0.023 \mathrm{M}$ ammonium citrate and $12 \%$ acetonitrile, and spotted in 3- $\mu 1$ volumes on a polished MTP AnchorChip ${ }^{\mathrm{TM}}$ plate (Bruker Daltonics). Mass spectra were acquired with the aid of installed software (flexcontrol 3.0) on a Microflex linear MALDI-TOF mass spectrometer (Bruker Daltonics).

Direct sequencing for HPV. DNA (4 $\mu \mathrm{l})$ was amplified with PGMY09/11 primer sets and purified with the QIAquick PCR purification kit (Qiagen) according to the manufacturer's instructions. Purified amplicons were sequenced with the BioDyeR Terminator v3.1 Cycle Sequencing kit (Applied Biosystems, Foster City, CA, USA). The resulting sequences were compared to HPV reference sequences from the Los Alamos National Laboratories HPV Database (http://hpv-web. lanl.gov) using Clustal $\mathrm{X}$ and Genedoc softwares.

Type-specific PCR for HPV types 18 and 16. A subset of clone mixtures that showed incorrect results with either RFMP or sequencing was amplified with type-specific HPV primers to verify the adequacy of the mixtures. Type-specific PCR primer sets were: 16 F-5'-GCACAGGGCCACAATAATGG-3'; 16 R-5'GGGAGGTTGTAGACCAAAATTCCA-3'; 18 F-5'GCACAG GGTCATAACAATGG-3'; 18 R-5'-CGGGGGGGGAACACC AAAGTTCCA-3'. After initial denaturation at $94^{\circ} \mathrm{C}$ for $5 \mathrm{~min}$, 70 cycles of $94^{\circ} \mathrm{C}$ for $15 \mathrm{sec}, 55^{\circ} \mathrm{C}$ for $15 \mathrm{sec}$ and $72^{\circ} \mathrm{C}$ for $30 \mathrm{sec}$ were performed. Final extension was at $72^{\circ} \mathrm{C}$ for $5 \mathrm{~min}$. PCR products $(5 \mu \mathrm{l})$ were electrophoresed on a $2 \%$ agarose gel and the remaining products were sequenced to verify the type of HPV amplified.

\section{Results}

Limits of detection for PCR-RFMP and sequencing. The PCR-RFMP assay had a lower LOD than direct sequencing, as calculated by probit analysis at the $95 \%$ positivity level when 25 replicates of HPV DNA were tested (Table I). As shown in Table II, the LODs for PCR-RFMP and sequencing were 21 vs. 496 copies/ml for type 16,424 vs. 429 copies/ml for type 18 and 1,162 vs. 4,542 copies/ml for type 11 , respectively.

Identification of double infection of HPV genotypes. The PCR-RFMP assay was $100 \%$ accurate when the three types of clone mixtures were used to detect double HPV infections. However, direct sequencing detected only type 16 in type $16+18$ mixtures and type 11 in type 18+11 mixtures. Sequencing failed to find any HPV in $16+11$ mixtures (Table III). The mixtures that were incorrectly typed by direct sequencing were verified to be authentic by amplifying HPV types 16 and 18 separately using type-specific primers (data not shown). 
Table I. Positive rate of each concentration of HPV DNA when 25 replicates of each concentration were tested by PCR-RFMP and direct sequencing.

\begin{tabular}{|c|c|c|c|c|}
\hline \multirow[t]{2}{*}{ HPV } & \multicolumn{2}{|c|}{ PCR-RFMP } & \multicolumn{2}{|c|}{ Sequencing } \\
\hline & Positive/tested & $(\%)$ & Positive/tested & $(\%)$ \\
\hline \multicolumn{5}{|l|}{ Type 16} \\
\hline $2.5 \times 10^{5}$ & $25 / 25$ & 100 & $25 / 25$ & 100 \\
\hline $2.5 \times 10^{4}$ & $25 / 25$ & 100 & $25 / 25$ & 100 \\
\hline $2.5 \times 10^{3}$ & $25 / 25$ & 100 & $25 / 25$ & 100 \\
\hline $2.5 \times 10^{2}$ & $25 / 25$ & 100 & $23 / 25$ & 92 \\
\hline $2.5 \times 10^{1}$ & $25 / 25$ & 100 & $0 / 25$ & 0 \\
\hline $2.5 \times 10^{0}$ & $3 / 25$ & 12 & $0 / 25$ & 0 \\
\hline $2.5 \times 10^{-1}$ & $2 / 25$ & 8 & $0 / 25$ & 0 \\
\hline \multicolumn{5}{|l|}{ Type 18} \\
\hline $2.5 \times 10^{5}$ & $25 / 25$ & 100 & $25 / 25$ & 100 \\
\hline $2.5 \times 10^{4}$ & $25 / 25$ & 100 & $25 / 25$ & 100 \\
\hline $2.5 \times 10^{3}$ & $25 / 25$ & 100 & $25 / 25$ & 100 \\
\hline $2.5 \times 10^{2}$ & $24 / 25$ & 96 & $21 / 25$ & 84 \\
\hline $2.5 \times 10^{1}$ & $4 / 25$ & 16 & $9 / 25$ & 36 \\
\hline $2.5 \times 10^{0}$ & $1 / 25$ & 4 & $0 / 25$ & 0 \\
\hline $2.5 \times 10^{-1}$ & $0 / 25$ & 0 & $0 / 25$ & 0 \\
\hline \multicolumn{5}{|l|}{ Type 11} \\
\hline $2.5 \times 10^{5}$ & $25 / 25$ & 100 & $25 / 25$ & 100 \\
\hline $2.5 \times 10^{4}$ & $25 / 25$ & 100 & $25 / 25$ & 100 \\
\hline $2.5 \times 10^{3}$ & $25 / 25$ & 100 & $20 / 25$ & 80 \\
\hline $2.5 \times 10^{2}$ & $16 / 25$ & 64 & $6 / 25$ & 24 \\
\hline $2.5 \times 10^{1}$ & $0 / 25$ & 0 & $0 / 25$ & 0 \\
\hline $2.5 \times 10^{0}$ & $0 / 25$ & 0 & $0 / 25$ & 0 \\
\hline $2.5 \times 10^{-1}$ & $0 / 25$ & 0 & $0 / 25$ & 0 \\
\hline
\end{tabular}

Concordance between PCR-RFMP and direct sequencing. Upon analysis of the 423 clinical specimens, the agreement between the two methods was $91.0 \%$ with a $\kappa$-value of 0.86 (Table IV). The detailed agreement in clinical specimens stratified by 5 cytological classes is summarized in Table V.

Detection of multiple HPV infection. Of the 423 clinical specimens, 348 (82.3\%) and 334 (79.0\%) were HPV-positive as determined by PCR-RFMP and direct sequencing, respectively. The incidence of multiple HPV infection among HPV-positive patients was $19.0 \%(66 / 348)$ by PCR-RFMP and 5.4\% (18/334) by sequencing (Table VI).

Clinical performance of PCR-RFMP and direct sequencing. Out of 423 cases, 101 were followed-up with a biopsy. According to the initial cytology, 5 cases were normal, 49 were LSIL, 23 were HSIL and 24 were squamous cell carcinoma.

Histological diagnosis of a lower grade than cervical intraepithelial neoplasm (CIN) 2 was considered as diseasepositive, and test results containing at least one high-risk HPV type were considered test-positive. Among the 101 histologically diagnosised specimens, 50 were disease-positive. Test positivity related to histological grade is shown in Table VII.
Table II. Limits of detection (LODs) of the PCR-RFMP and direct sequencing calculated by probit analysis at the $95 \%$ positivity level.

\begin{tabular}{lcc}
\hline HPV type & \multicolumn{2}{c}{ LOD (copies/ $\mu 1)$} \\
\cline { 2 - 3 } & PCR-RFMP & Sequencing \\
\hline Type 16 & 424 & 496 \\
Type 18 & 1,162 & 429 \\
Type 11 & 4,592 \\
\hline LOD for each HPV type was calculated based on the data shown in \\
Table I.
\end{tabular}

Table III. Identification of double HPV infections in three types of clone mixtures.

\begin{tabular}{|c|c|c|c|c|}
\hline & Ratio & $\begin{array}{c}\text { Replicate } \\
\text { no. }{ }^{\text {a }}\end{array}$ & $\begin{array}{l}\text { PCR- } \\
\text { RFMP }\end{array}$ & Sequencing \\
\hline \multicolumn{5}{|l|}{ Type $16+18$} \\
\hline & $9: 1$ & 5 & $16+18$ & 16 \\
\hline & $8: 2$ & 5 & $16+18$ & 16 \\
\hline & $5: 5$ & 5 & $16+18$ & 16 \\
\hline & $2: 8$ & 5 & $16+18$ & 16 \\
\hline & $1: 9$ & 5 & $16+18$ & 16 \\
\hline \multicolumn{5}{|l|}{ Type $16+11$} \\
\hline & $9: 1$ & 5 & $16+11$ & $\begin{array}{c}\text { Mixture } \\
\text { (not defined) }\end{array}$ \\
\hline & $8: 2$ & 5 & $16+11$ & $\begin{array}{c}\text { Mixture } \\
\text { (not defined) }\end{array}$ \\
\hline & $5: 5$ & 5 & $16+11$ & $\begin{array}{c}\text { Mixture } \\
\text { (not defined) }\end{array}$ \\
\hline & $2: 8$ & 5 & $16+11$ & $\begin{array}{c}\text { Mixture } \\
\text { (not defined) }\end{array}$ \\
\hline & $1: 9$ & 5 & $16+11$ & $\begin{array}{c}\text { Mixture } \\
\text { (not defined) }\end{array}$ \\
\hline
\end{tabular}

Type $18+11$

$\begin{array}{llll}9: 1 & 5 & 18+11 & 11 \\ 8: 2 & 5 & 18+11 & 11 \\ 5: 5 & 5 & 18+11 & 11 \\ 2: 8 & 5 & 18+11 & 11 \\ 1: 9 & 5 & 18+11 & 11\end{array}$

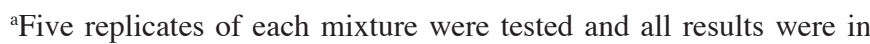
agreement. The authenticity of all mixtures incorrectly typed by sequencing was verified using type-specific PCR.

Clinical sensitivity, specificity, and positive and negative predictive value calculations are shown in Table VIII.

\section{Discussion}

We evaluated the analytical sensitivity and the clinical utility of a newly developed HPV genotyping tool, the PCR-RFMP 
Table IV. Comparison of the results of PCR-RFMP and direct sequencing with respect to carcinogenic risk categories of HPV.

\begin{tabular}{|c|c|c|c|c|}
\hline \multirow{2}{*}{$\begin{array}{l}\text { No. (\%) of specimens with } \\
\text { the indicated results }\end{array}$} & \multicolumn{4}{|c|}{ Sequencing } \\
\hline & HR & OTH & NEG & Total \\
\hline \multicolumn{5}{|l|}{ PCR-RFMP } \\
\hline HR & $198(46.8)$ & $16 \quad(3.8)$ & $7 \quad(1.7)$ & $221 \quad(52.3)$ \\
\hline OTH & $8 \quad(1.9)$ & $112(26.5)$ & $7 \quad(1.7)$ & $127 \quad(30.0)$ \\
\hline NEG & $0 \quad(0.0)$ & $0 \quad(0.0)$ & 75 (17.6) & $75 \quad(17.7)$ \\
\hline Total & $206(48.7)$ & $128(30.3)$ & $89(21.0)$ & $423(100.0)$ \\
\hline
\end{tabular}

The HPV carcinogenic risk categories were as follows: HPV types 16, 18, 31, 33, 35, 39, 51, 52, 56, 58, 59 and 66 were classified as 'high-risk' (HR) genotypes, and the remainder as 'other' (OTH) genotypes. NEG, HPV-negative results.

Table V. Concordance between the results of PCR-RFMP and direct sequencing, with respect to cytological diagnosis.

\begin{tabular}{|c|c|c|c|}
\hline \multirow{2}{*}{$\begin{array}{l}\text { Cytological } \\
\text { diagnosis }\end{array}$} & \multirow[t]{2}{*}{ No. of specimens } & \multicolumn{2}{|c|}{ Concordance between RFMP and sequencing } \\
\hline & & Agreement (\%) & $\kappa$-value $(95 \% \mathrm{CI})$ \\
\hline NL & 50 & 88.0 & $0.79(0.63-0.94)$ \\
\hline ASCUS & 100 & 89.0 & $0.83(0.74-0.93)$ \\
\hline LSIL & 157 & 91.1 & $0.84(0.76-0.92)$ \\
\hline HSIL & 92 & 94.6 & $0.65(0.36-0.93)$ \\
\hline $\mathrm{SCC}$ & 24 & 91.7 & $0.76(0.45-1.00)$ \\
\hline Total & 423 & 91.0 & $0.86(0.81-0.90)$ \\
\hline
\end{tabular}

NL, normal; ASCUS, atypical squamous cells of undetermined significance; LSIL, low-grade squamous intraepithelial lesion; HSIL, highgrade squamous intraepithelial lesion; SCC, squamous cell carcinoma.

assay. The assay had a higher analytical sensitivity, expressed as a lower LOD, compared to the well-established automated direct sequencing method of genotyping. The performance of the new assay in the detection and identification of double HPV infections was excellent. When clinical specimens were tested, good agreement was found between the PCR-RFMP assay and direct sequencing data.

This is the first study to evaluate the analytical sensitivity and detection accuracy of multiple HPV infections using the PCR-RFMP assay and model mixtures of cloned HPV genomes. Only one previous report on the utility of PCR-RFMP for HPV genotyping has been published (13). In that study, cervical scrapes from $50 \mathrm{HPV}$-positive patients were used, whereas we employed 423 clinical specimens covering all cytological stages from normal to SCC. This may explain the relatively lower concordance rate $(385 / 423,91.0 \%)$ between PCR-RFMP and sequencing data in the present study, compared to that of the cited study $(49 / 50,98.0 \%)$.

The differences in HPV type-specific sensitivities observed in the present study may be caused by mismatches between primers and HPV sequences. An earlier study found that $\mathrm{GP}^{+} / 6^{+} \mathrm{PCR}$ was of lower sensitivity when used to detect HPV types 53 and 61 than MY09/11 PCR. However, MY09/11 PCR was less sensitive when used to detect HPV type 35 (14). A PGMY09/11 reverse line blot test, using the same primers as those employed in the PCR-RFMP assay, offered a higher detection rate for HPV types 42, 56 and 59, compared to the results of the SPF10-PCR test (15).

Ultra-sensitivity of an HPV DNA test is not necessarily clinically desirable, as this may encourage unnecessary followup involving colposcopy and further treatment, possibly resulting in a negative obstetric outcome (16). However, with the advent of HPV vaccines, a high analytical sensitivity of HPV genotyping is necessary in order to monitor the efficacy of prophylactic HPV vaccination. This is an issue that is clearly different from the clinically relevant sensitivity value (17).

Turning to the ability of the tests to detect multiple infections, PCR-RFMP was $100 \%$ accurate when mixtures of cloned HPV DNA were evaluated. Conventional sequencing was not satisfactory when double infections were present, revealing a limitation of the fluorescence-based assay. When clinical specimens were tested, PCR-RFMP found a 19\% (66/348) incidence of multiple HPV infections among HPV-positive women, whereas sequencing detected a frequency of only $5.4 \%$ (18/334). Thus, variation in methodological accuracy may affect the detected frequencies of multiple HPV infection in epidemiological studies. Variable proportions of HPV-positive women with multiple infections have been previously reported; frequencies ranged from $11.5 \%$ in Turin, Italy (18), to $42.4 \%$ in Ho Chi Minh City, Vietnam (19).

In the present study, the agreement in HPV genotyping data between the PCR-RFMP assay and direct sequencing 
Table VI. Type of detection of HPV infection by PCR-RFMP and direct sequencing.

\begin{tabular}{|c|c|c|c|c|c|c|}
\hline \multirow[b]{2}{*}{ Type of infection } & \multicolumn{6}{|c|}{ PCR-RFMP } \\
\hline & NL & ASCUS & LSIL & HSIL & SCC & Total $(\%)$ \\
\hline Negative & 28 & 37 & 8 & 1 & 1 & 75 \\
\hline Single & 20 & 52 & 108 & 78 & 19 & 277 \\
\hline Multiple & 1 & 10 & 39 & 13 & 3 & 66 \\
\hline Undetermined & 1 & 1 & 2 & 0 & 1 & 5 \\
\hline \multirow[t]{2}{*}{ Total } & 50 & 100 & 157 & 92 & 24 & 423 \\
\hline & \multicolumn{6}{|c|}{ Sequencing } \\
\hline Type of infection & NL & ASCUS & LSIL & HSIL & SCC & Total $(\%)$ \\
\hline Negative & 32 & 42 & 11 & 3 & 1 & 89 \\
\hline Single & 16 & 50 & 131 & 85 & 19 & 301 \\
\hline Multiple & 0 & 5 & 9 & 4 & 0 & 18 \\
\hline Undetermined & 2 & 3 & 6 & 0 & 4 & 15 \\
\hline Total & 50 & 100 & 157 & 92 & 24 & 423 \\
\hline
\end{tabular}

NL, normal; ASCUS, atypical squamous cells of undetermined significance; LSIL, low-grade squamous intraepithelial lesion; HSIL, highgrade squamous intraepithelial lesion; SCC, squamous cell carcinoma.

Table VII. Positivity test with respect to histological grades.

\begin{tabular}{lccccc}
\hline \multirow{2}{*}{$\begin{array}{l}\text { Histological } \\
\text { grades }\end{array}$} & \multicolumn{2}{c}{ PCR-RFMP } & & \multicolumn{2}{c}{ Sequencing } \\
\cline { 2 - 3 } \cline { 5 - 6 } & Test (+) & Test (-) & & Test (+) $)^{\mathrm{a}}$ & Test (-) \\
\hline Negative & 18 & 20 & & 11 & 27 \\
CIN1 & 5 & 8 & & 8 & 5 \\
CIN2 & 18 & 0 & & 17 & 1 \\
CIN3 & 8 & 0 & & 7 & 1 \\
SCC & 20 & 4 & & 18 & 6 \\
Total & 69 & 32 & & 61 & 40
\end{tabular}

${ }^{\mathrm{a}} \mathrm{A}$ result containing at least one high-risk HPV type was considered as test (+), otherwise as (-). CIN, cervical intraepithelial neoplasm.

gradually increased as the extent of cytological abnormality increased from normal $(44 / 50,88.0 \%)$ to HSIL $(87 / 92,94.6 \%)$. However, concordance decreased to $91.7 \%$ when SCC samples $(22 / 24)$ were tested, which may be explained by the smaller sample size of the SCC group. Generally, higher agreement between various HPV test methods becomes evident as the cytological grading of cervical scrapes tends towards a more advanced pathological grade (20).

A limitation of the present study is that the clinical sensitivity or specificity of the PCR-RFMP method could not be fully investigated. Due to the short duration or loss of follow-up, only 101 histologically diagnosed cases out of 423 cytological specimens were available for evaluation. Although the proportion of histologically confirmed cases was not satisfactory, the clinical sensitivity of PCR-RFMP was
Table VIII. Clinical performances of PCR-RFMP and direct sequencing for HPV genotyping.

\begin{tabular}{lccccc}
\hline & \multicolumn{2}{c}{ PCR-RFMP } & & \multicolumn{2}{c}{ Sequencing } \\
\cline { 2 - 3 } \cline { 5 - 6 } & Test $(+)^{\mathrm{a}}$ & Test (-) & & Test $(+)^{\mathrm{a}}$ & Test (-) \\
\hline Disease (+) & 46 & 4 & & 42 & 8 \\
Disease (-) & 23 & 28 & & 19 & 32 \\
\hline Clin sensi & $(46 / 50) \times 100=92 \%$ & & $(42 / 50) \times 100=84 \%$ \\
Clin spec & $(28 / 51) \times 100=55 \%$ & & $(32 / 51) \times 100=63 \%$ \\
PPV & $(46 / 69) \times 100=67 \%$ & & $(42 / 61) \times 100=69 \%$ \\
NPV & $(28 / 32) \times 100=88 \%$ & & $(32 / 40) \times 100=80 \%$
\end{tabular}

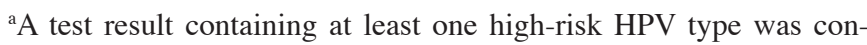
sidered as test $(+) .{ }^{b}$ Histological diagnosis with a lower grade than cervical intraepithelial neoplasm (CIN) 2 was considered as disease (+). Clin sensi, clinical sensitivity; Clin spec, clinical specificity; PPV, positive predictive value; NPV, negative predictive value.

still better than that of direct sequencing. Further examination of patients with confirmed clinical outcomes, and for whom histological diagnoses are available, will validate the clinical utility of HPV genotyping using the PCR-RFMP assay.

In conclusion, we demonstrated that HPV testing using the recently introduced PCR-RFMP assay offers high analytical and clinical sensitivity and the advantage of reliable detection of multiple HPV infections. Good correlation with direct sequencing data was apparent when clinical specimens were tested. 


\section{Acknowledgements}

The study was supported by a grant from the Korean Healthcare Technology R\&D Project, Ministry of Health and Welfare, Republic of Korea (no. A084507).

\section{References}

1. GLOBOCAN 2008, International Agency for Research on Cancer: Section for Cancer Information: Cervical Cancer Incidence and Mortality Worldwide in 2008. http://globocan. iarc.fr/factsheets/cancers/cervix.asp. Accessed Oct 16, 2010.

2. De Villiers EM, Fauquet C, Broker TR, et al: Classification of papillomaviruses. Virology 324: 17-27, 2004.

3. Munoz N, Bosch FX, de Sanjose S, et al: Epidemiologic classification of human papillomavirus types associated with cervical cancer. N Engl J Med 348: 518-527, 2003.

4. Brown DR, Schroeder JM, Bryan JT, et al: Detection of multiple human papillomavirus types in Condylomata acuminata lesions from otherwise healthy and immunosuppressed patients. J Clin Microbiol 37: 3316-3322, 1999.

5. Gale N, Poljak M, Kambic V, et al: Laryngeal papillomatosis: molecular, histopathological, and clinical evaluation. Virchows Arch 425: 291-295, 1994

6. Bosch FX, Burchell AN, Schiffman M, et al: Epidemiology and natural history of human papillomavirus infections and type-specific implications in cervical neoplasia. Vaccine 26 (Suppl 10): 1-16, 2008.

7. Hong SP, Kim NK, Hwang SG, et al: Detection of hepatitis B virus YMDD variants using mass spectrometric analysis of oligonucleotide fragments. J Hepatol 40: 837-844, 2004.

8. Lee CH, Kim SO, Byun KS, et al: Predominance of hepatitis B virus YMDD mutants is prognostic of viral DNA breakthrough. Gastroenterology 130: 1144-1152, 2006.

9. Kim HS, Han KH, Ahn SH, et al: Evaluation of methods for monitoring drug resistance in chronic hepatitis B patients during lamivudine therapy based on mass spectrometry and reverse hybridization. Antivir Ther 10: 441-449, 2005.
10. Kim YJ, Kim SO, Chung HJ, et al: Population genotyping of hepatitis $\mathrm{C}$ virus by matrix-assisted laser desorption/ionization time-of-flight mass spectrometry analysis of short DNA fragments. Clin Chem 51: 1123-1131, 2005.

11. Hong SP, Shin SK, Lee EH, et al: High-resolution human papillomavirus genotyping by MALDI-TOF mass spectrometry. Nat Protoc 3: 1476-1484, 2008.

12. Gravitt PE, Peyton CL, Alessi TQ, et al: Improved amplification of genital human papillomaviruses. J Clin Microbiol 38: 357-361, 2000.

13. Lee EH, Chung HJ, Oh HB, et al: Human papillomavirus genotyping assay using restriction fragment mass polymorphism analysis, and its comparison with sequencing and hybrid capture assays. Korean J Lab Med 27: 62-68, 2007.

14. Qu W, Jiang G, Cruz Y, et al: PCR detection of human papillomavirus: comparison between MY09/MY11 and GP5+/GP6+ primer systems. J Clin Microbiol 35: 1304-1310, 1997.

15. Van Doorn LJ, Quint W, Kleter B, et al: Genotyping of human papillomavirus in liquid cytology cervical specimens by the PGMY line blot assay and the SPF (10) line probe assay. J Clin Microbiol 40: 979-983, 2002.

16. Kyrgiou M, Koliopoulos G, Martin-Hirsch P, et al: Obstetric outcomes after conservative treatment for intraepithelial or early invasive cervical lesions: systematic review and meta-analysis. Lancet 367: 489-498, 2006.

17. Snijders PJ, van den Brule AJ and Meijer CJ: The clinical relevance of human papillomavirus testing: relationship between analytical and clinical sensitivity. J Pathol 201: 1-6, 2003.

18. Ronco G, Ghisetti V, Segnan N, et al: Prevalence of human papillomavirus infection in women in Turin, Italy. Eur J Cancer 41 297-305, 2005

19. Clifford GM, Rana RK, Franceschi S, et al: Human papillomavirus genotype distribution in low-grade cervical lesions: comparison by geographic region and with cervical cancer. Cancer Epidemiol Biomarkers Prev 14: 1157-1164, 2005.

20. Ermel A, Qadadri B, Morishita A, et al: Human papillomavirus detection and typing in thin prep cervical cytologic specimens comparing the Digene Hybrid Capture II Assay, the Roche Linear Array HPV Genotyping Assay, and the Kurabo GeneSquare Microarray Assay. J Virol Methods 169: 154-161, 2010. 